Article

\title{
On the Design of Social Media for Learning
}

\author{
Jon Dron ${ }^{1, *}$ and Terry Anderson ${ }^{2}$
}

1 School of Computing and Information Systems, Athabasca University, 1 University Drive, Athabasca, AB T9S 3A3, Canada

2 Centre for Distance Education, Athabasca University, 1 University Drive, Athabasca, AB T9S 3A3, Canada; E-Mail: terrya@athabascau.ca

* Author to whom correspondence should be addressed; E-Mail: jond@athabascau.ca; Tel.:+1-866-916-9634.

Received: 9 May 2014; in revised form: 22 July 2014 / Accepted: 31 July 2014 /

Published: 8 August 2014

\begin{abstract}
This paper presents two conceptual models that we have developed for understanding ways that social media can support learning. One model relates to the "social" aspect of social media, describing the different ways that people can learn with and from each other, in one or more of three social forms: groups, networks and sets. The other model relates to the 'media' side of social media, describing how technologies are constructed and the roles that people play in creating and enacting them, treating them in terms of softness and hardness. The two models are complementary: neither provides a complete picture but, in combination, they help to explain how and why different uses of social media may succeed or fail and, as importantly, are intended to help us design learning activities that make most effective use of the technologies. We offer some suggestions as to how media used to support different social forms can be softened and hardened for different kinds of learning applications.
\end{abstract}

Keywords: social media; design; learning technology; online learning

\section{Introduction: Social Systems for Learning}

Social media allow people to learn from and with one another in many different ways. Typically, however, neither teachers nor learners are provided with much conceptual training or support for either understanding or making the design decisions so that they can anticipate and channel the effects of 
social media on learning. They are thus left to their own devices and whatever support can be gained from their learning networks to use or create learning technologies that actually perform the work of helping people to learn. This paper is intended to help bridge that gap, to provide some components of a conceptual framework that we hope will help those building or using social media for learning. We present and relate perspectives on social technologies for learning: the first concerns the social forms that such technologies support; the second deals with the nature and structure of those technologies. We have written about each of these perspectives separately in the past [1,2] and found them useful as distinct tools for understanding social systems. Together, they provide a consolidated lens for examining our practices, and a means to think about how to use and create social technologies to support learning and teaching in different social learning contexts.

\section{Social Forms and Social Learning}

Before we begin it is helpful to remind ourselves why it is worthwhile to learn with other people because, without knowing the purpose, it is not possible to begin to use tools effectively. These are of some of the more notable benefits of learning with others:

- Our relationship with others is fundamental to our sense of self and meaning. Doing things with and for others is one of the major pillars supporting intrinsic motivation [3]. We are inherently social creatures [4]. Other people provide support, help, affirmation and challenge.

- Expressing our conceptions and opinions in a way meant to be understood by those around us is a form of teaching. Teaching is a great way to learn: having to explicitly construct or reconstruct our own knowledge in a manner that allows others to learn and understand us allows us to strengthen and make connections between ideas, and reflect on our own skills and how they are formed, rehearse things we may do by habit or have forgotten. In Pask's conversation theory this is the critically important linchpin of learning that he calls 'teachback' [5]. It also underpins constructionist accounts of learning and pedagogy [6], in which it is as important to share what we create as it is to create it.

- Seeing how other people understand the same ideas and problems, reflecting on the differences, helps us to critique and refine our own understanding of the world. Other people help us see things differently, from multiple perspectives [7]. Even if we disagree, the resulting cognitive dissonance helps us to think about how and why we disagree. Beyond problem solving, in many cases, such diversity can help everyone be more creative by providing a greater range of ideas, themes or facts that suggest further possibilities. The classic 'brainstorm' approach makes significant use of this simple dynamic.

- A problem shared is a problem halved: people have diverse and varied knowledge and skills to share, and can introduce us to new ideas, new facts, new ways of doing and new ways of seeing. Diverse perspectives make everyone in a community smarter [8]. Moreover, sharing the learning load spreads more knowledge around a community with greater efficiency than an individual could manage alone. Knowledge is infectious, a non-rival good that spreads through a community like fire.

- Discussion with others, especially with those playing a teaching role (who may often be other learners) allows us to seek clarification when things are unclear, inform people when they are 
stating the obvious, and take greater control of our own learning. A sense of being in control is another of the pillars of intrinsic motivation [3]. Dialogue gives not only choice but the power to exercise that choice in an informed way [9].

- Closely related to control, the final pillar of intrinsic motivation is for learning tasks to be sufficiently challenging, not within our existing capabilities, nor so far beyond them that they confuse us or frighten us [10]. Negotiation between learner and the person playing a teaching role makes it easier to ensure that this point has been reached. This concept relates closely to the notion of a zone of proximal development that Vygotsky sees as the space where teachers can effectively support learners to attain new knowledge [11].

- The motivation and opportunities for engagement afforded by others naturally increases the time on task spent learning. The more we engage actively in learning, the more we learn, and this alone may be sufficient to account for a strong positive correlation between interaction with others and learning success [12].

- Many types of knowledge do not exist outside of the social culture in which they can be expressed and understood.

In summary, social systems can be of huge value in learning at least in part because they provide motivation, diversity and amplification of knowledge and, often, a context for its construction and expression. They can, however, be both divisive and distracting, thus there is a need for a clear conceptual grounding to understand both their benefits and their risks.

\section{Sets, Nets, Groups and Collectives}

Classrooms, tutorial groups, schools and universities as well as large and small employers have long provided supportive processes and communities with which and from which to learn. As new social media have developed it has become increasingly clear that, though community building and close connection remain significant and important, many benefits of social learning, including distributed problem solving, teachback, negotiation of paths and, especially, diversity of perspectives, do not rely on communities or classes of the traditional kind. We are and have always been supported in our learning by broader networks of people we know. Popular sites like Twitter and Facebook demonstrate the ease of sharing and connection that is making our networks increasing valuable as a source of knowledge and help. Beyond that, there is not just a vast amount of information available on the Internet as a whole but enormous numbers of people that we do not know, yet who may teach us, support us, and help us to solve our problems. This is poorly charted territory: we know a great deal about how intentionally formed, purpose-built groups can assist our learning, but we know far less about how it can happen in the kind of collections of people linked together through social media, on the web and through mobile apps. To help understand this and as a means of bringing conceptual order to guide more effective use, we have found it useful to think of social media as supporting varying mixtures of three basic social forms: the group, the network and the set. In brief:

- Groups are named entities that have structures, roles, norms, rules for joining and leaving, purposes and, normally, schedules. They are the familiar form of most intentional learning, including classes, tutorial groups, schools, work teams and committees. The fact that they 
contain processes and structures means that they are fundamentally technological in naturegroups are intentionally formed, designed and maintained by the people that lead them and/or their other members, using formal or informal rules and norms. Learning management systems, content management systems and groupware tools are typical examples of online tools built to support groups, and provide support for the processes that enable a group to function and achieve its purposes.

- Networks are the people we know. They are emergent and largely unplanned, identifiable in retrospect but shifting all the time. They have no deliberate rules, no fixed purpose, no formal name, though we can label them (e.g. "my friends", "my teachers", etc). As the use of the word 'my' indicates, they are defined egocentrically [13]. Email, social networking sites, blogs and instant messaging are common tools to support networks.

- Sets are people we likely do not know as individuals but who share known common attributes such as interests, abilities or location. Like networks, they do not normally have defining rules or structure, beyond the attributes that define them, although tools to support them may implement methods and structures to sustain them. They become significant in a learning context when, either intentionally or through software, people in a set share the same virtual or physical space and may thus affect, influence, help or hinder one another. Social interest sites, curation sites, location-oriented tools, Q\&A sites, and public wikis like Wikipedia are common tools to support sets.

The three social forms can blend and coexist among the same people at the same time and more than one form may be supported by a single toolset. Twitter's hashtags, for instance, support sets because they focus solely on interests, while its 'following' functionality can support networks because it is at least partly about people we know, or wish to know (notwithstanding the fact that following may equally be used in a more set-oriented way, such as when following a hockey team or company). The three social forms are more like primary colours that can be infinitely mixed than discrete categories, but most social collections of people, especially on the Internet, have greater tendencies towards one particular form than another. In addition, the social forms may morph into each other. For example a class group may become an informal network after a course has finished, and will quite naturally morph to join a set of alumni.

Emerging from and helping to shape any of these social forms, especially sets and networks, are collectives. A collective (a term that we use rather than 'collective intelligence' as it can potentially be as much a manifestation of collective stupidity as of collective wisdom) is the result of the actions of many people that, through a process of aggregation or transformation, may be treated as though it were a single entity. For example, Google's PageRank recommendations, Amazon's media recommendations, counts of votes for answers on a Q\&A site, or tag clouds that suggest relevant topics, are all collectives: they are single agents, typically playing recommendation or organizing roles that are not unlike those that might be played by individual people. As a result of being formed from the combined individual behaviours of many intelligently acting people, collectives can appear to be quite intelligent and, under the right conditions, can magnify the intelligence of a crowd or harness crowd knowledge and preferences to help individuals to achieve their goals [14,15]. Collectives can play an important role in many social media systems, acting as filters, recommenders and even generators of content and 
ideas, as well as means to discover and assess the credibility, reliability or even fuzzier facets such as likeability or compatibility of people. Interestingly, these may thus play some of the roles of a teacher in discovering, organizing and filtering information that may help us learn, as well as enabling us to discover people who may assist on our learning journeys.

Each social form has strengths and weaknesses. Groups, for instance, are particularly good for intentional planned learning, for instilling trust, for working with others towards a common goal. On the other hand, they impose constraints on individual freedom, scale very poorly, embed power structures that may not be helpful, and can lead to a lack of diversity [14], or group-think [16]. Networks are great for freedom, improve (up to a point), as they get bigger and the social capital formed within them can be a powerful motivator [17]. On the other hand, they lack structure, purpose and intention, being defined egocentrically and lacking processes or direction. They can also lead to filter bubbles and echo chambers [18], where we only connect with those we agree with and see what we have seen before. Sets (in the absence of collectives) offer the greatest freedom of all, are by nature are structured around individual interests, scale very well indeed (more is better) and can provide immense diversity. However, they suffer from lack of trust in both individuals and what they say, offer little social capital for motivation, and lack process and sequence to support learning. All of these issues can be greatly improved through the use of collectives to provide structure, filtering and critique, but collectives can as easily be a force for ignorance as they can for wisdom, being no smarter than the methods used to combine individual behaviours and a potent source of filter bubbles. It is beyond the scope of this paper to delve too deeply into these strengths and weaknesses but, for a far more detailed discussion of social forms and collectives, and the ways they can be used in designing learning activities, see [2]. Figure 1 illustrates the blending of the social forms, providing some typical examples of the kinds of social aggregations that occur on and between their boundaries. We seek to illustrate here that collectives can emerge as a result of and aid in the growth of any of the social forms but are quite different in nature from those forms.

Figure 1. Sets, nets, groups, collectives and some examples of typical forms they take.

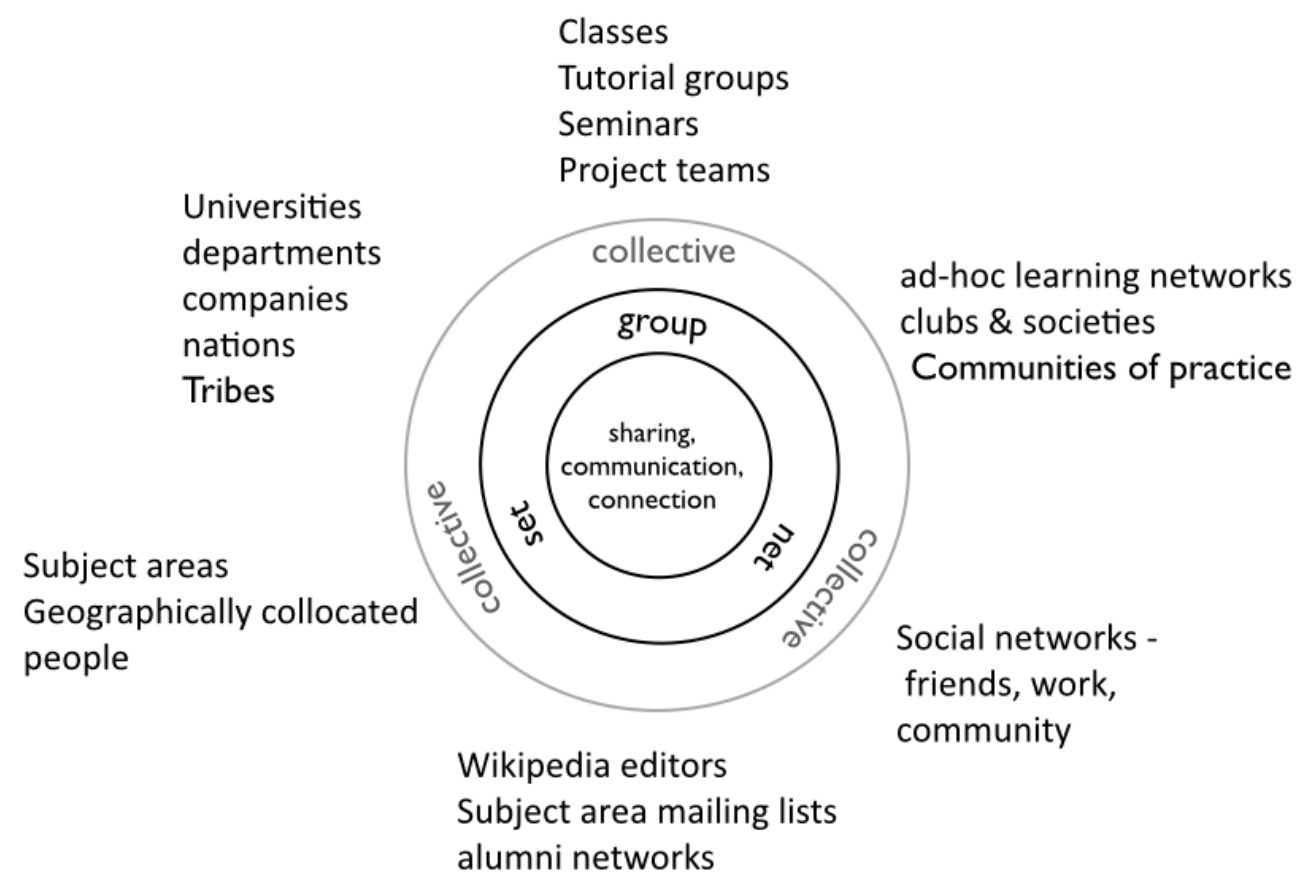


Understanding the different ways that people may interact with one another through social media is only one part of the problem of effective use. We must also understand the role that such media play in shaping and assisting these forms, and how they may be assembled to do that. Our discussion is not about the detailed practical skills of manipulating toolsets but relates to the role and nature of technologies in general.

\section{A Structural Model of Learning Technologies}

If we are to support learning through social media it is important to understand the nature of the toolsets we are using. It appears at first glance that no single toolset is the answer to all online teaching and learning problems; otherwise it would dominate the market and likely be as ridiculous as a foot wide Swiss Army knife. Looking deeper, however, this is more complicated. There are low-level toolsets that play exactly that all-purpose role-operating systems, programming languages and, at a deeper level, the hardware, protocols and machine-code instructions that make computers work and interoperate. However, the skills needed to build systems using only these low-level tools are thinly dispersed and would, even for those with sufficient expertise, require a much greater amount of effort and time than that required to build systems with higher-level toolkits such as learning management systems (LMSs). Few would dream of building an online learning tool using nothing but machine code or even a relatively high-level programming language like FORTRAN, though early pioneers such as the creators of among the very earliest of computer-based learning systems, PLATO, were forced to do so. Such general-purpose programming languages are incredibly flexible, but incredibly hard to use to build complex software systems, requiring a lot of painstaking effort to write, debug and test.

We do not need to be system programmers, however, to face a need for an enormous range of skills and decisions in building social learning systems. At the user-facing end, there are many very flexible general-purpose toolkits that can be bent to a huge diversity of purposes. Email, for instance, could be used to replace almost all, if not all, the functions of a group-oriented tool like a learning management system (LMS) if we put our minds to it. The main feature set of an LMS will typically include tools to enable publication and organization of course materials, discussions, discretionary access control, assignment submission and marking. All of this could be done using email. Publication, discussions and submission of assignments are straightforward to manage using email as long as we share a list of recipients, manually follow a protocol in the use of subject lines, switch off spam filters, and everyone involved manages received and sent mail carefully. Some discretionary access control is possible through sending emails to selected individuals. Assessment management might demand a little more manual effort, probably involving a complex process involving sent-items folders and BCC functionality, as well as the need to manually process marking totals. It can be done, but it would be massively prone to error, it would require a lot of thought and effort on the part of all concerned, it would be slow, and it would be frustrating.

\subsection{Soft and Hard Technologies}

The examples of email and machine code highlight a crucial distinction between softer and harder technologies. All technologies are orchestrations of phenomena to some use [19]. Harder technologies embed much of the orchestration of complex tasks within the toolset itself, while softer ones leave 
much of that orchestration to people. This means that softer technologies increase the choices available, yet, the more choices that have to be made, the more difficult it is for people to choose between them [20]. Harder technologies make the choices for us and so, at least in that important regard, tend to be easier to use. However, too much hardness can take away the potential for creativity, flexibility and adaptability which, in a learning context, can be quite harmful, whether it affects teachers trying to use technologies to teach, or learners trying to use them to learn. The requisite balance varies in every enactment of a technology: there is always a trade-off between soft flexibility and hard efficiency. Soft is hard, hard is easy [1].

Because all technologies are assemblies of other technologies [19], often mutually constitutive, and the assembly usually contains a mix of soft and hard pieces, almost all technologies are assemblies that lie on a continuum between soft and hard. Few, if any, technologies are purely hard or purely soft.

Not only is this not a binary distinction, but it varies according to perspective and context. What may be soft for one person may be hard for another. To a programmer, for instance, a computer can be a very soft technology while to a student using a locked-down objective test system using exactly the same computer and software (albeit in a different configuration) it may be very hard. This is because the parts of the orchestration being handled by people differ in each case: a programmer is responsible for a lot of decisions while very few will be allowed for the student taking the test. Similarly, an LMS may be very soft for a teacher creating a course, but very hard for a student taking it because different phenomena are being orchestrated for different ends. The fact that the physical tools carry the same name and denotation blinds us to the fact that they are in fact different technologies, thanks to the differences in processes and in uses to which they are put. When examining a technology it is important to consider the entire assembly rather than to focus on just one of its more obvious parts. An LMS is only part of the teaching and learning machine, not what defines it.

Methods, techniques, procedures, organizational designs and processes are technologies, so it follows that the techniques, methods and processes that we use to teach are as much a part of the technological assembly as anything else, and can be hard or soft like any other technology.

Hard systems may often be softened by aggregating them with others, while soft systems can be hardened by replacing soft processes with hard tools or procedures. For example, if an assignment submission system restricts timing or length of submission, a teacher might soften this by asking for students to submit work via email, accepting the increased effort and unreliability that this entails as a trade-off for increased flexibility. Similarly, if a tool or process is confusing, unreliable or slow, a harder component may be added to replace it. For example, a teacher who is unable to cope with assignments being submitted at any time may impose strict deadlines to replace this soft process and potentially automate this using an LMS.

We have found this orchestral perspective on soft and hard technologies to be quite valuable in helping to understand and explain a wide variety of behaviours and effects of technologies in learning. It allows us to focus on the importance of how things are done with at least as much emphasis as what is done. This helps to avoid sweeping generalizations such as those often found in comparisons between online and face-to-face learning that pay no heed to methods, processes, contexts and cultures, and it allows for richer analyses of technologically-enhanced systems that recognizes the varying roles of humans in both enacting and in using technologies. Though valuable as a lens for examining digital media, it allows us to see technologies as embedded on a continuum in which 
timetables and pedagogies are as much a concern as LMSs and tablets. For a more detailed examination of these hard and soft technology concepts see [1].

\subsection{Soft and Hard Social Media}

A distinctive feature of all social media used for learning is that they are inherently soft technologies, for all concerned, teachers and students alike. They are not simply composed of bytes but also of the purposes, epistemologies, rules \& regulations, ethical norms, pedagogies, motivations, and the broad and interlocking systems of the people that use them. Each instance of the same software is a part of a different social architecture and so a different social technology even though it may use the same machinery and be referred to by a common name. This is particularly apparent in the case of groups, whose deliberate design, norms, rules and structures are technological in nature and form a necessary part of the description of any technological assembly to which they belong. However, even in nets and sets that are not rule-bound or inherently technological in nature, emergent behaviours can occur as a result of human interactions rather than through deliberate design, or may spring from structural or demographic features. The set attribute of being a teacher, for example, tends to be accompanied by a number of other attributes_attitudes, qualifications, interests and behaviours. A set of teachers is thus likely to have a very different range of interests, activities and behaviours than a set of students and so will use the tools differently. There will be different patterns of engagement. Other behaviours may emerge as a result of interactions between people in a network: a network of friends, for instance, may pass ideas, knowledge and attitudes within it, including the spread of memes and attitudes, which will mean that the ways that one social network is used and the kinds of interactions within it will differ from another, even when centered on the same individual. For example, our engagement with other academics in a network is typically quite different from our engagement with our families. This can be quite confusing when those networks overlap and we, say, shift between formal and less formal vernacular on Twitter, or use vocabularies that are only meaningful to one of our networks. Different behaviours in groups, sets and networks can be promoted or discouraged through design of both social processes (in the educational case, often learning activities) and through the design and configuration of software or hardware used to mediate them. The kinds of functionality available as well as what is emphasized and de-emphasized in the physical form (interface) may strongly influence the kinds of behaviour that result. For example, the very constrained 140-character limit of Twitter does not explicitly prevent any particular kind of interaction from occurring, thanks to the availability of hyperlinks and hooks into other services such as photo-sharing, but it tends to encourage a staccato flow of focused tweets that is entirely different from what is normally seen in an online discussion forum, which are different again from face-to-face conversations.

\subsection{Hardening and Softening}

When thinking about designs of social software systems we must take into account not only the structural and process support of the software environment but the behaviour of individuals and the effects of mutual interactions that are overlaid on top of these. Anderson [21] describes this as a dance between pedagogy and technology but it is more than this: it is a dance between all the many processes, cultural norms, methods and tools that go into making up the character of any given 
technology in any given context. The choice of when and how to make things harder or softer depends on many things and differs according to whose needs are being met: teachers, for example, typically need different things to be softened and hardened than learners, but there is also enormous diversity among learners and what may suit one person at one time may not suit her for a different need at a different time. We may also be highly constrained in our choice of toolset: even if we know that our needs could be met better by a different tool, we may not be able to use it for reasons of conformity with the needs and access of others, cost, complexity, unwanted extra features, privacy legislation and so on. However, wherever possible, the most important central principle to follow is that we should harden what needs to be hardened, and soften what needs to be softened. The key concern is to orchestrate wisely: as much as possible, to harden things that do not contribute to the learning process using tools and designs that require little thought, while maintaining softness and flexibility where the process of orchestration itself has value in learning, and where the exercise of creativity should be both supported and encouraged.

\subsection{A Simple Example}

In a classroom setting, for example, a teacher may require that blog posts or comments should be posted in a particular format or place, according to a particular schedule, in response to particular posts, and so on. This human-enacted hardening of a soft social media system can be problematic, however, as it requires students to follow instructions precisely. There are at least two difficulties with this. In the first place, people make mistakes, so this can quickly degenerate into chaos, making it hard for everyone involved to find information or engage with others. Secondly, it requires substantial effort on the part of students to perform organizational tasks that may not contribute to what they intend to learn in any meaningful way. As much as possible, therefore, the nature and structure of learning activities and outputs should align with the available tools. In this example, it may be more effective to use a different tool, such as a wiki, that allows the teacher to create links, a hierarchical structure and perhaps a template, to help reduce the cognitive load for the students so that fewer choices that are irrelevant to the learning task need to be made. Alternatively, he or she might allow students to post anywhere but make use of an RSS aggregator to overlay the necessary structure, or perhaps even aggregate (manually or using additional web 2.0 tools) links to posts in a separate place.

\subsection{Hardening and Softening in Groups}

In broad terms, systems built to support the learning needs of a group need hardening along lines that embody the structure, roles, processes, regulations and methods used by that group. Because groups are essentially designed structures, it tends to be relatively straightforward to embody those designs in software, as long as we have sufficient control over the software to do that. Learning management systems tend to do this by simply replicating the structure, organization and processes of typical existing institutional or business structures used in face-to-face learning — classes, assessments, lectures and discussion groups are typically simply reproduced in software form. However, this can be confusing should the model of the LMS differ from that of the institution or course. It is important to be aware of and ideally avoid building or using an LMS with a different organizational schema than that of the group(s) that it is hosting. We have often seen such issues. Some can be small but still have 
an impact: For example, hard-coded use of the word "course" in an LMS when institutions that host it use "module" or "paper" can lead to unnecessary confusion, especially where the word "course" has a different meaning (such as in the UK, where "course" is typically used in a manner resembling "program" in North America). Some mismatches can have more far-reaching effects: for example, the first author once ran a program distributed across multiple institutions with both centralized and decentralized resources and both planned and unplanned engagement across and between sites. We therefore created a custom-built LMS so that those in outlying institutions could engage with those in other institutions while maintaining local connections and discussions. As a result of this custom design, during its early years, much was gained through sharing of knowledge across sites. When, due to resource constraints, we were forced to move to a Blackboard system that lacked the capacity to support such networked organization, cross-site engagement fell significantly and each site became more isolated [22]. An institutional model of the educational process is often made concrete in software even when such systems are intended to operate outside institutional environments, such as in the case of MOOCs (massive open online courses). This may not be the most appropriate approach, and is certainly not a good idea if we wish to make use of different social forms. For example, a tool that hardens a teacher role into a hierarchy of rights and facilities allowed within a system may be a poor match when we wish to encourage an open generative or democratic pedagogy or even to allow the teacher to play a more background role within a learning transaction.

At a pragmatic level, groups typically need tools that can support collaboration-roles, scheduling, sharing, authentication, authorization, calendars, workflows, versioning and project management tools all have a place in helping to sustain a collaborative process, where people work together in an organized way to achieve a mutually valuable end. Again, it is useful if these are either hardened to accurately reflect the ways collaboration is expected to happen, or that the system is sufficiently soft to allow multiple different procedures to be used.

\subsection{Hardening and Softening in Nets}

Networks are innately soft and resistant to hardening of most kinds.

They are built on trust and personal connection, not according to roles and regulations. Indeed, such roles and regulations are anathema to the growth of healthy networks. Rules of behaviour may have little meaning or value in network-oriented systems - if I am communicating with a network of friends then it would, for example, be too much of an imposition to require that I never swear or tell jokes, let alone tie them to schedules, methods assessments or processes to follow.

While networks themselves may be soft, tools to support them still shape their development. Hardening in networks should mostly be concerned with reinforcing network ties, alerting members to relevant activities, simplifying communication and sharing, and helping people to structure, make sense of and yet not be overwhelmed by their networks. Facebook's growth, for example, has become such a problem that it now displays only a fraction of updates from a user's network, but the problem can afflict any sufficiently active network. Few of us pay attention to every tweet that passes by, for instance and, even if we did, learning is seldom a result of every post that we view. Systems such as the Circles functionality in Google+ or the similar Collections feature of Elgg can go a long way to helping with this problem, by allowing individuals to parcellate their networks into manageable 
chunks. Similarly, tags or hashtags that divide a network into sets of relevant posts can help prevent social network overload for the intentional learner. Filters can help to ensure that learners engage with the right people in their networks to provide them with navigational assistance.

It is also useful in networks to provide tools that simplify the act of making a connection with another person. In harder networks, reciprocal friending of the sort found in Facebook or LinkedIn may have value because reciprocity helps to ensure that trust relationships between individuals are strong. However, a weaker 'following' connection of the sort found in Twitter, may encourage greater connectivity and allow for a freer flow of ideas. If the learner is the one that follows then the implication is that there is some reason to trust that the one followed will provide value. It can be very useful to employ individual profiles that act both as a single point for sharing with others and a means to find and come to know others in a network. Encouraging pride in the development of complete profiles can be achieved through simple digital tools like 'completeness' widgets and simple interfaces to build them, but softer approaches such as the establishment of social norms, and more direct cajoling, can have at least as much or more effect. It can be useful to make use of status casting, even so far as to tell the network that you have fed your cat, in order to sustain a sense of connection and network presence [7]. As a general rule, networks are grown rather than designed and, through reciprocity, sharing and encouragement, can be nurtured like gardens so that they grow strong. A stronger network can sustain learning more effectively in part because it means there are more opportunities to interact, in part because of the social capital that can be used to seek and provide help. Bearing in mind that all networks are, from an individual's perspective, unique to them, it is important for individuals to develop the soft skills of good network citizenship.

Finally, networks should simplify the sharing and construction of knowledge. Hard, efficient tools are needed that make sharing and communication easy. It is not enough to simply provide the means to connect and share with others, in addition the toolsets provided should make content creation and sharing simple to do, and easy to digest for the viewer. This tends to become more problematic as toolsets gain features, which is an almost inevitable result of the softening process of technology evolution [19], and as social networks themselves become too large to handle. The softer and more malleable they become, the more difficult they are to use. There is an almost inevitable dynamic towards increased complexity or feature bloat as greater numbers of increasingly diverse users make use of such systems, demanding ever more features and ever greater refinements to meet ever more diverse needs. This is one reason that new social networking systems with clear foci and distinct roles are often able to take over market segments where incumbents once seemed unassailable.

One way to change this balance is through the use of collectives. For example, Facebook's EdgeRank algorithm [23] that makes use of the closeness of network ties, post novelty and user-determined weightings (amongst other things) is used to filter and reduce the flow of status updates that users see to more manageable levels. Though most users therefore only see a fraction of what might have been shared, this extra hardening makes it easier to handle the flow and, if done well, can show things that are most relevant to the user. Unfortunately, for most social networking systems, pedagogical reasons tend to play a negligible role in determining what is shown. This remains a significant research area though, for now, the most effective means to deal with this problem is either through features like lists (Facebook), circles (Google) or collections (Elgg), or through the use of 
systems focused on specific communities such as Academia.edu, that allow networks to be organized by the learner into distinct clusters that are relevant to their learning needs.

\subsection{Hardening and Softening in Sets}

Sets tend to be hard in the sense that they delimit the range of topics or interests according to a fixed set of attributes but, because involvement with a set is entirely voluntary and often lacking strong commitment, and because sets have no innate social structure, they tend to the softer end of social forms from an end-user perspective. This softness can make learning in sets problematic. While sets open up enormous opportunities to benefit from diverse perspectives and the combinatorial wisdom of a crowd, beyond narrowing down to a particular topic or subject area, it can be very hard to find relevant help, and even harder to ascertain its validity or usefulness. Moreover, people in sets are typically unknown and so harder to trust, especially as sets are often feeding grounds for trolls and other malicious or unhelpful users. Even if they are trustworthy the people in a set may be uninformed or communicate badly. A lot of time can be wasted when trying to learn in sets, unless further mechanisms are instituted to lessen the harm caused by their lack of social structure.

Much of this boils down to trust, whether of people or information, so we need to find ways either to negate the need for it or to identify whether a person or resource is trustworthy. Collectives can and often do play a strong role here, to a large extent replacing human roles in determining trustworthiness. For example:

- Badges, karma points and other measures of reputation can be useful to help identify the right people in a set though should be used with care as they may actually reduce intrinsic motivation by substituting for the purpose of the activity [24]. They may have value in sets because they can help signal the expertise or willingness to help of people who may solve our learning problems.

- The up and down user-recommendation or ratings tools on Q\&A sites like those in the StackExchange family or Reddit can help to draw attention to useful or less useful resources. If the collective process is sufficiently well designed and there is a sufficient user base to counter the effects of deliberate manipulation, this hardening can make such sites both pedagogically valuable (useful answers are those that make sense) and reliable (useful answers are accurate).

- Tagging, and associated tag clouds, can be a very useful way to create structure out of a disorganized whole without the need to control it from the top down.

Tag clouds make use of the dynamics of stigmergy [25] a particularly valuable form of collective self-organizing behaviour that has seen much application in the field of complex adaptive systems for learning and in other fields (e.g., [26,27]. Stigmergy emerges through reactions to signs left in the environment by other individuals engaged in the same activity (e.g., forest footpaths, termite mounds, movements of money markets), and it can strongly influence behaviours in such systems, allowing the crowd to guide the individual to useful and reliable people, paths and resources. The collective that results can often act much like a teacher: Google Search, for example, plays a teacher role in recommending pages to visit and is stigmergically driven [28] as are some aspects of Wikipedia [29] which is among the most useful teachers in the world. However, stigmergic collectives are subject to risks like the Matthew Effect (the rich get richer) [30], preferential attachment (obsolete patterns 
persist) [31], and filter bubbles (selection patterns that increasingly limit diversity) [18]. An awareness of these problems can help a learner to overcome them, though they remain an ongoing issue for set-based learners.

Deliberate collaboration is rarely, if ever, found in sets. The dominant model of working with others is instead cooperative. In a cooperative model, people work separately but their work contributes to the common good. Examples include the sharing of work, blog posts and bookmarks, answering of questions in Q\&A sites, as well as more interdependent activities such as independent edits of wiki pages. Hardening support for cooperation demands some means of sharing outputs, and a mechanism for organizing them. A good example of this is that of GitHub, where sets of people with a shared interest in a particular program or code library are supported in sharing the workload through GitHub's toolset which, amongst other things, allows programmers to 'fork' one another's code and return it to the originator through "pull requests", without ever having to know anything about the people, processes and goals of others involved. Wikipedia provides a related approach, in which a combination of top-down structure and templates provided by the site and the soft security resulting from many eyes and the ease with which changes can be undone compensates for the lack of group rules and norms.

\section{Conclusions}

To make effective use of social media for learning, it is useful to understand both the ways that social systems can support learning and the ways that technologies fit together and support such systems. The softness of social systems means that they are infinitely malleable, although this does not mean we have infinite choice over how to implement them. Different choices constrain others, pushing us down different and constantly forking paths. Building effective social learning systems to meet the needs of the learners and teachers within them involves making choices about which aspects are of most importance to the social and learning context, and where trade-offs are made. It is, however, important to remember that learning is about change. Therefore, if there are no changes, there is a good chance that our system is not working as effectively as it might. This means that these concerns will always be ongoing and that social systems will be in a constant state of flux. They will evolve, whatever control we exert on them, and we must never stop adapting to that evolution. We hope that by providing relatively simple abstract models to describe the variables involved, the discussion that we have provided here may be of some value in negotiating this complex shifting landscape. These models may enable us to design and use social technologies (including all their softer and harder elements) to more effectively and purposefully support learning.

\section{Acknowledgments}

This is a translated, modified and extended version of a paper originally published in Spanish as 'Diseñando medios sociales para el aprendizaje' in the open journal Revista Mexicana de Bachillerato a Distancia, 11, septiembre 2013-febrero 2014. 


\section{Author Contributions}

Both authors contributed equally to the model of social forms. Jon Dron developed the soft/hard model with support from Terry Anderson, and both authors contributed to the mapping between the two. Jon Dron prepared most of the manuscript with substantial contributions from Terry Anderson.

\section{Conflicts of Interest}

The authors declare no conflict of interest.

\section{References}

1. Dron, Jon. “Soft is Hard and Hard is Easy: Learning Technologies and Social Media.” Form@re 13 (2013): 32-43.

2. Dron, Jon, and Terry Anderson. Teaching Crowds: Social Media and Distance Learning. Athabasca: AU Press, 2014.

3. Deci, Edward L., and Richard M. Ryan. "Self-Determination Theory: A Macrotheory of Human Motivation, Development and Health.” Canadian Psychology 49 (2008): 182-85.

4. Wilson, Edward O. The Social Conquest of Earth. New York: Liveright Corporation, 2012.

5. Pask, Gordon. Conversation Theory-Applications in Education and Epistemology. New York: Elsevier, 1976.

6. Papert, Seymour, and Idit Harel. "Situating Constructionism.” In Constructionism. Edited by Seymour Papert and Idit Harel. Wesport: Ablex Publishing Corporation, 1991.

7. McCracken, Grant. "Status Casting and Persistent Friends." Anthropology of Contemporary Culture, 2007. Available online: http://cultureby.com/2007/12/status-casting.html (accessed on 5 August 2014).

8. Page, Scott E. The Difference: How the Power of Diversity Creates Better Groups, Firms, Schools, and Societies (New Edition). Princeton: Princeton University Press, 2008.

9. Garrison, D. Randy, and Myra Baynton. "Beyond Independence in Distance Education: The Concept of Control.” American Journal of Distance Education 1 (1987): 3-15.

10. Deci, Edward L., and Arlen C. Moller. "The Concept of Competence: A Starting Place for Understanding Intrinsic Motivation and Self-Determined Extrinsic Motivation.” In Handbook of Competence and Motivation. Edited by J. Andrew Elliot and S. Carol Dweck. New York: The Guilford Press, 2005, pp. 579-97.

11. Vygotsky, Lev S. Mind and Society: The Development of Higher Psychological Processes. Cambridge: Harvard University Press, 1978.

12. Hwang, Wu-Yuin, and Chin-Yu Wang. "A Study of Learning Time Patterns in Asynchronous Learning Environments.” Journal of Computer Assisted Learning 20 (2004): 292-304.

13. Rainie, Lee, and Barry Wellman. Networked. Cambridge: MIT Press, 2012.

14. Page, Scott E. Diversity and Complexity. Princeton: Princeton University Press, 2011. 
15. Surowiecki, James. Independent Individuals and Wise Crowds. IT Converstaions, 468, 2005. Available online: http://web.archive.org/web/20130729210015id_/ http://itc.conversationsnetwork.org/shows/detail468.html (accessed on 5 August 2014).

16. Baron, Robert S. "So Right it’s Wrong: Groupthink and the Ubiquitous Nature of Polarized Group Decision Making." In Advances in Experimental Social Psychology. San Diego: Elsevier Academic Press, 2005, vol. 37, pp. 29-253.

17. Ellison, Nicole B., Charles Steinfield, and Cliff Lampe. "The Benefits of Facebook 'Friends': Social Capital and College Students’ Use of Online Social Network Sites.” Journal of ComputerMediated Communication 12 (2007): 1143-68.

18. Pariser, Eli. The Filter Bubble: What the Internet is Hiding from You. New York: Penguin, 2011.

19. Arthur, W. Brian. The Nature of Technology: What it is and How it Evolves. New York: Free Press, 2009.

20. Schwartz, Barry. The Paradox of Choice: Why Less is More. New York: HarperCollins, 2004.

21. Anderson, Terry. "The Dance of Technology and Pedagogy in Self-Paced Distance Education." Paper presented at the 17th ICDE World Congress, Maastricht, Netherlands, 2009. Available online: http://hdl.handle.net/2149/2210 (accessed on 3 August 2014).

22. Dron, Jon, Catharine Seidel, and Gabrielle Litten. "Getting the Right Blend: A Blended- Learning Approach to Foundation Degree Delivery.” In Making Foundation Degrees Work. Edited by Lyn Brennan and David Gosling. London: SEEC, 2004.

23. Wilson, Brian. "The Recreation of Time and Space: Google and Facebook.” 2011. Available online: http://brianjameswilson.com/recreation-of-time-space-google-facebook.html (accessed on 5 August 2014).

24. Kohn, Alfie. Punished by Rewards: The Trouble with Gold Stars, Incentive Plans, a'S, Praise, and Other Bribes. Boston: Mariner Books, 1999.

25. Grassé, Pierre-Paul. "La Reconstruction Du Nid Et Les Coordinations Inter-Individuelles Chez Bellicoitermes Natalenis Et Cubitermes Sp. La Theorie De La Stigmergie: Essai D’interpretation Des Termites Constructeurs.” Insect Societies 6 (1959): 41-83.

26. Den Besten, Matthis. Loris Gaio, Alessandro Rossi, and Jean-Michel Dalle. "Using Metadata Signals to Support Stigmergy." Self-Adaptive and Self-Organizing Systems Workshop (SASOW), 2010 Fourth IEEE International Conference, Budapest, Hungary, 27 September-1 October 2010; Los Alamitos: IEEE Computer Society, 2010, pp. 131-35.

27. Gutiérrez, Sergio, Abelardo Pardo, and Carlos Delgado Kloos. "Finding a Learning Path: Toward a Swarm Intelligence Approach.” 5th IASTED international conference on Web-based education, Puerto Vallarta, Mexico, 23-25 January 2006; Calgary: ACTA Press, 2006, pp. 94-99.

28. Gregorio, Joe. "Stigmergy and the World-Wide Web." 2003. Available online: http://bitworking.org/news/Stigmergy (accessed on 5 August 2014)

29. Heylighen, Francis. "Why is Open Access Development So Successful? Stigmergic Organization and the Economics of Information.” In Open Source Jahrbuch 2007. Edited by Bernd Lutterbeck, Matthias Bärwolff and Robert A. Gehring. Berlin: Lehmanns Media, 2007. 
30. Merton, Robert K. "The Matthew Effect in Science: The reward and communication systems of science are considered.” Science 159 (1968): 56-63.

31. Kearns, Michael, Siddharth Suri, and Nick Montfort. "An Experimental Study of the Coloring Problem on Human Subject Networks.” Science 313 (2006): 824-27.

(C) 2014 by the authors; licensee MDPI, Basel, Switzerland. This article is an open access article distributed under the terms and conditions of the Creative Commons Attribution license (http://creativecommons.org/licenses/by/3.0/). 